\title{
The effects of hope and type $C$ personality on social relational quality and acceptance of disability among breast cancer survivors: mediating role of medical coping style
}

\author{
Xiaoying Shen ( $\sim$ sxy13351883728@163.com ) \\ Harbin Medical University \\ Runna Miao \\ Xi'an Jiaotong University \\ Yuping Lin \\ Fudan University \\ Hui Sun \\ Heilongjiang Provincial Hospital \\ Wei Yang \\ Heilongjiang Provincial Hospital
}

\section{Research Article}

Keywords: acceptance of disability, breast cancer, coping style, hope, social relationship quality, type C personality

Posted Date: May 10th, 2021

DOI: https://doi.org/10.21203/rs.3.rs-426370/v1

License: (a) This work is licensed under a Creative Commons Attribution 4.0 International License.

Read Full License 


\section{Abstract}

Objective: Previous studies have shown that the hope of breast cancer survivors is related to the social relational quality, and personality is related to acceptance of disability. However, research is still limited about the underlying potential psychological mechanisms of various psycho-social factors for this population. This study aims to investigate the impact of breast cancer survivors' hope and type $\mathrm{C}$ personality on social relational quality and acceptance of disability, and to evaluate the mediating effect of medical coping styles.

Methods: A total of 150 breast cancer survivors during chemotherapy were recruited from Harbin, China completed a self-reported questionnaire containing the personal information questionnaire, Herth hope index ( $\mathrm{HHI})$, Type $\mathrm{C}$ behavior scale, Medical coping modes questionnaire (MCMQ), Social relationship quality scale (SRQS) and acceptance of disability scale (ADS).

Results: Results showed that the proposed model fitted the data very well $\left(c^{2}=8.357, d f=7, p=0.302\right.$, $\left.c^{2} / d f=1.194, \mathrm{GFI}=0.981, \mathrm{CFI}=0.991, \mathrm{TLI}=0.982, \mathrm{RMSEA}=0.037\right)$. Further analyses revealed that, Confrontation mediated the relationship between hope and social relationship quality (indirect effect $=0.034, \mathrm{BC} 95 \% \mathrm{Cl}=0.001 \sim 0.106$ ), and acceptance-Resignation mediated the relationship between type $\mathrm{C}$ personality and acceptance of disability (indirect effect $=-0.379, \mathrm{BC} 95 \% \mathrm{Cl}=-0.637 \sim-0.145$ ).

Conclusions: Confrontation and acceptance-Resignation played critical roles in the relationship between hope, type $\mathrm{C}$ personality and social relational quality, the acceptance of disability. Healthcare practitioners should be aware of the coping strategies of breast cancer survivors, and psycho-social interventions and supportive care should focus on these cognitive and emotional processes to improve social relational quality and acceptance of disability for this population.

\section{Introduction}

Breast cancer is one of the most common malignant tumors in the world and the main cause of death for women. According to the latest global cancer data released by the International Agency for Research on Cancer (IARC) of the World Health Organization in 2020, there are as many as 2.26 million new cases of breast cancer. Meanwhile, breast cancer ranks first in the number of new cases and has become the fourth leading cause of death among female cancer in China [1]. The current treatment of breast cancer is based on surgery combined with chemotherapy and radiotherapy and other comprehensive treatment methods. Although the improvement of the treatment plan has significantly improved the survival rate of breast cancer survivors (5-year survival rate is $90 \%, 10$-year survival rate is $80 \%$ ) [2], which caused patients to experience more physical pain and psychological torture, which seriously affects the quality of life [3]. Therefore, healthcare practitioners should focus on breast cancer survivors' response to cancer trauma and adaptation, including physical, psychological, and social aspects, which to improve the quality of life [4-7]. 
Research shows that social relationships are an important factor affecting the physical and mental health of patients, and can affect instrumental and emotional support for cancer survivors [8]. Hou W [9] puts forward the concept of social relational quality based on the social and cultural background of Asian populations. He believes that Asian people pay more attention to maintaining interpersonal and emotional health and harmonious relationships when coping with stress. Especially for Chinese patients who tend to be collectivist, the quality of social relationships is the core of their family and social life [10]. As a positive internal support force, 'hope' can encourage patients to overcome difficulties, relieve pain and stress. Hope is an important strategy for cancer patients to cope with the disease [11]. Studies have shown that breast cancer survivors with high levels of hope can obtain a higher quality of life and are more satisfied with their social relationships [12]. In recent years, studies have confirmed that there is a certain correlation between the social relational quality and hope among breast cancer survivors [13], but the underlying psychological mechanism of them still needs further research.

Previous studies have shown that type $C$ personality was a predictive variable of breast cancer [14]. According to the theoretical model proposed by Temoshok, the mainly important personality factors which can increase the psychological risk factors for breast cancer are emotional depression and compliance with others, that is type $C$ personality, also known as 'cancer susceptibility personality' [15]. It can induce tumors through psycho-physiological and immunological mechanisms, thereby reducing the therapeutic effect of cancer patients and affecting the development and prognosis of the disease trajectory [16]. In addition, due to physical disability and impaired self-esteem, breast cancer survivors are more likely to show type $C$ personality than other cancers [17]. Studies have shown that breast cancer survivors with good personality characteristics are less likely to develop chemotherapy related symptoms, and are better able to adapt to the adverse physical and mental effects of postoperative chemotherapy [18ه19].

As early as 1950, Grayson proposed the concept of acceptance of disability. It was further refined by Wright in 1960 depending on accepting the concept of loss, and gradually developed into a theory of individual subjective meaning of loss. It is understood from the following four dimensions that people's reaction to loss and attitudes, including enlargement of scope of values, transformation from comparative values to asset values, containment of disability effect, and subordination of physique [20]. During the treatment of breast cancer survivors, mastectomy will not only destroy the integrity of the body, but also reduce the unique charm of women and significantly increase the physical and mental burden of the patient [3]. Studies have shown that psycho-social factors have a significant predictive effect on the acceptance of disability among breast cancer survivors, including the social relational quality and medical coping styles [6]. Therefore, in-depth exploration of the relationship between type $C$ personality and disability acceptance is essential for understanding and determining strategies for the mental health of breast cancer survivors.

Medical coping styles mainly include three coping strategies, which are confrontation, avoidance, acceptance-Resignation. Studies have found that confrontation and acceptance-resignation can be used as predictors of the degree of disability adaptation of breast cancer survivors [6]. Previous studies have 
shown that in the trajectory of breast cancer disease, coping styles have a certain correlation with personality traits [21]. And the coping style also shows a better predictive effect in the path relationship mediated by the hope, psychological flexibility [22], acceptance of disability and quality of life [23] of breast cancer survivors.

At present, the mediating effect of medical coping styles on the hope and type $C$ personality on the social relational quality and acceptance of disability of breast cancer survivors has not been confirmed at home and abroad. Therefore, this study aims to clarify the direct and indirect relationship between breast cancer survivors' hope, type $\mathrm{C}$ personality, social relational quality, and acceptance of disability, and to explore the mediation mechanism of medical coping styles in breast cancer survivors. Based on the existing theoretical frameworks and empirical studies, we hypothesized that a ideal level of hope can improve the social relational quality and acceptance of disability of breast cancer survivors through active coping. While breast cancer survivors with a type $C$ personality can adopt acceptance-resignation, thereby weakening the degree of adaptation to physical and functional disability caused by surgery ( figure 1 for the structural model).

\section{Methods}

\subsection{Participants and procedure}

A total of 150 breast cancer survivors were recruited, which were selected from September 2019 to December 2020 in the breast surgery ward in the affiliated Hospital of Harbin Medical University. Inclusion criteria were: 1) diagnosed pathologically as breast cancer, and is undergoing postoperative chemotherapy for breast cancer, 2) female patients $\geq 18$ years of age, 3) ability to read Chinese. Exclusion criteria were: 1) Past history of mental illness, severe mental or cognitive dysfunction, 2) accompanied by severe physical illness or past other malignant tumors and recurrence, 3 ) type of surgery patients who take breast-conserving conservative treatment. A total of 141 (94\%) patients admitted to the hospital were eligible and agreed to participate in the study. $20.57 \%$ of the participants were under the age of $45.60 .99 \%$ were within $45-59$ years and $18.44 \%$ were over 60 years old. Table 1 presents the detailed sample characteristics.

Ethical approval for this study was obtained from the Research Ethics Committee at Harbin Medical University (NO.KY2019-0118). Before the survey, the researchers were strictly trained. During the survey, the researchers explained the purpose and significance of the survey to the patients. After obtaining the patient's informed consent, they used a unified instruction to explain the questionnaire filling method and precautions to the patients. After the questionnaire is completed, it will be retrieved on the spot to check whether there are missing or invalid items, and if necessary, instruct patients to fill in or fill up again, and each participant was given a small gift after completed the study.

\subsection{Measures}

\subsubsection{Personal information questionnaire}


Designed by the researcher according to the research purpose and the characteristics of the disease, which including age, education, marital status and other demographic and sociological data.

\subsubsection{Herth hope index}

The Herth hope index $(\mathrm{HHI})$ was used to measure hope about breast cancer. The Chinese version of the scale was introduced in 1999 by the translation of Zhao Haiping from China Medical University [24]. The 12-item scale has 3 subscales: temporality and future $(T)$, positive readiness and expectancy $(P)$, and interconnectedness (I). Using the Liket 4-level scoring method, each item is rated from 1 (strongly disagree) to 4 (strongly agree) and total score ranges from 12 to 48 , with higher score reflecting greater hope. The internal consistency reliability of the scale Cronbach's a coefficient is 0.85 .

\subsubsection{Type $\mathrm{C}$ behavior scale}

Designed by Temoshok and introduced to China by Yan Hua et al [25]. There are 16 items of C-type behavior pattern, and the score range is 0-16 points. The higher the score, the more obvious the type $\mathrm{C}$ personality behavior tendency, and the incidence, recurrence and metastasis rate of cancer are significantly increased. It has been widely used in patients after breast cancer surgery. The Cronbach's a coefficient of this questionnaire is 0.745 [25].

\subsubsection{Medical coping modes questionnaire}

The Medical Coping Modes Questionnaire (MCMQ) compiled by Feifei in 1987, the Chinese version was revised by Jiang Qianjin [26]. It has been widely used to assess patient coping patterns, including 19 items under the three dimensions of confrontation, avoidance, and acceptance-resignation. Each item is scored using a 4-point Likert rating that ranges from $1=$ never to $4=$ very much. The Cronbach's a coefficients of the three subscales in Chinese breast cancer patients are $0.803,0.723,0.7426$, respectively [6].

\subsubsection{Social relational quality scale}

The Social Relational Quality Scale (SRQS) was designed by Hou [9] to assess the quality of social relationships in social processes. This 22-item scale is scored using a 4-point Likert scale that ranges from 1 = strongly disagree to 4 = strongly agree. It addresses the three dimensions of family intimacy, family commitment, and friendships, with higher scores representing higher levels of social relational quality. The Cronbach's a value was measured as 0.832 in Chinese breast cancer patients [6].

\subsubsection{Acceptance of disability scale}

Linkowski compiled the acceptance of disability scale (ADS) based on the theory of loss of acceptance in 1971 in order to describe the individual's attitude towards disability, and in 2007 it was revised by Darlene. The Chinese version of the scale was revised by Ni Chen et al [27]. The 32-item scale has 4 subscales: enlargement of scope of values, transformation from comparative values to asset values, 
containment of disability effect, and subordination of physique. The ADS is scored using a 4-point scale ranging from 'strongly disagree' (1) to 'strongly agree' (4), with higher scores indicating a higher level of ADS. The content validity index $(\mathrm{CVI})$ of the total scale is 0.919 , and the internal consistency reliability Cronbach's a value is 0.83 .

\subsection{Data analysis}

Using Epidata 3.1 for single and double data entry can ensure the accuracy of data entry. The SPSS24.0 and AMOS24.0 statistical software packages are used to process and analyze the data. The measurement data is described by the mean and standard deviation $(M \pm S D)$ is expressed. Perform descriptive statistics and correlation in SPSS24.0 to identify potential covariates. Examine the relationship between outcome variables ( $S R Q S$ and ADS), pre-variables (hope, type C personality), and medical coping styles. Path analyses were conducted using AMOS24.0 with maximum likelihood estimation. Model fit was accessed with the chi-square estimate, normed fit index (NFI), comparative fit index (CFI), Tucker-Lewis index (TLI), and the root mean square error of approximation (RMSEA). Model fit is deemed to be satisfactory if a CFI and TLI greater than 0.95 and an RMSEA less than 0.05 [28]. Indirect effects were assessed using the bootstrap procedure with bias-corrected $95 \% \mathrm{Cls}$.

\section{Results}

\subsection{Descriptive statistic and correlations}

The score of SRQS of breast cancer survivors during chemotherapy was 54.49 (SD=5.84), and the total mean score of ADS of breast cancer survivors during chemotherapy was 82.21 ( $S D=11.21$ ), which was at a moderate level. Breast cancer survivors' hope, confrontation and social relational quality are all positively correlated $(P<0.05)$, type $C$ personality and acceptance-resignation are significantly positively correlated $(P<0.01)$, and negatively correlated with ADS $(P<0.01)$, more details are in Table 2 . There is no correlation between the avoidance and each variable, so it does not enter the structural equation model.

\subsection{Path analysis}

Based on the above-mentioned results of the analysis of variables and literature review, the hope and type $C$ personality are used as pre-variables. Confrontation and acceptance-resignation in medical coping styles are used as intermediary variables. The SRQS and ADS are used as outcome variables. Then to build a structural equation model. During the calculation process, the hypothetical model is corrected and fitted according to the standard correction index. Results showed that the model had good fitness to the data, $c^{2}=8.357, d f=7, \mathrm{P}=0.302, \mathrm{c}^{2} / d f=1.194, \mathrm{GFI}=0.981, \mathrm{CFI}=0.991, \mathrm{TLI}=0.982, \mathrm{RMSEA}=0.037$. All the path coefficients were significant.

According to the model results, the total effect of the hope of breast cancer survivors and the SRQS (Point estimate $=0.841,95 \% \mathrm{Cl}_{\mathrm{bc}}=0.683$ to 1.008 ) and direct effect (point estimate $=0.807,95 \% \mathrm{Cl}_{\mathrm{bc}}=0.644$ to 0.976 ) both are significant. At the same time, confrontation as an intermediary factor between hope and 
SRQS, the indirect effect is (point estimate $=0.034,95 \% \mathrm{Cl}_{\mathrm{bc}}=0.001$ to 0.106 ). In addition, type $\mathrm{C}$ personality of breast cancer survivors has a significant negative predictive effect on ADS, and the total effect is (Point estimate $=-1.311,95 \% \mathrm{Cl}_{\mathrm{bc}}=-1.898$ to -0.871). Among them, the positive predictive effect of type $C$ personality on acceptance-resignation, the direct effect is (point estimate $=0.423,95 \% \mathrm{Cl}_{\mathrm{bc}}=0.256$ to 0.580 ), which is significant. The negative predictive effect of acceptance-resignation on ADS, and the direct effect is (point estimate $=-0.895,95 \% \mathrm{Cl}_{\mathrm{bc}}=-1.463$ to -0.235 ) was significant. The indirect effect of type $C$ personality on $A D S$ through acceptance-resignation is (point estimate $=-0.379,95 \% \mathrm{Cl}_{\mathrm{bc}}=-0.637$ to $-0.145)$, and the acceptance-resignation as an intermediate factor can explain the effect of $28.9 \%$ on ADS. The results show that the medical coping style has a significant mediating effect in the relationship between the hope and the type $\mathrm{C}$ personality on the SRQS and ADS (Figure 1 and Table 3).

\section{Discussion}

This study investigated the relationship between the hope, type C personality on the SRQS and ADS among breast cancer survivors, and the underlying psychological mechanisms. Consistent with our hypothesis, hope and confrontation can improve the SRQS among breast cancer survivors, while the type $C$ personality and acceptance-resignation can make breast cancer survivors have a significant level of adaptation to physical and functional disabilities reduce.

Among the 141 participants in this survey, the $\mathrm{HHI}$ total score is $37.11(\mathrm{SD}=4.38)$, which is at a high level of hope, with the same as the results of Zhang et al [29ه30]. The total score of SRQS of breast cancer survivors during chemotherapy is 54.49 ( $S D=5.84)$, which is consistent with the studies of Hou [9] in Hong Kong. Due to their unique cultural background, cancer patients in Asia normally pay more attention to support from family and friends and emphasize the importance of this support [31] than in European countries, which focus on maintaining the quality of couple relationships [32]. The reason may be that many breast cancer survivors are unable to accept the physical changes after mastectomy, lead to have a sense of inferiority. It leads to females being reluctant to share the diagnosis report and seek more support with others besides family members [33®34], so patients tend to receive emotional support and care from family members.

The results showed that type $\mathrm{C}$ personality score is $4.40(\mathrm{SD}=3.22)$, which is consistent with the research results of Jie Niu [35]. In the process of questionnaire collection and interviews with breast cancer survivors, it was found that some survivors were easy to control their emotions, suppressed their emotions. In the follow-up treatment, they showed hopelessness, pessimism, fear of facing reality, and even committing suicide. The postoperative ADS of the patients was 82.21 ( $S D=11.21$ ), which was at a moderately low level, which was consistent with the results of the study by Li Jianghua et al [36『37]. ADS has a positive effect on patients' physical and mental healing, self-acceptance and social role [38]. Patients undergoing modified radical mastectomy not only face the problems of arm function disorder and body image change in post-operation, but also multiple psychological pressures, including sadness, low self-esteem, pain and shame caused by treatment. Unable to accept a series of physical and 
psychological changes in a short period of time, resulting in a low level of ADS for patients [6]. Healthcare practitioners should adopt effective intervention to improve the quality of life of breast cancer survivors.

The hope of breast cancer survivors and the SRQS were positively correlated $(r=0.630, p<0.01)$. It indicated the higher the hope, the better the SRQS of breast cancer survivors. Further path analysis results showed that the hope has an indirect effect of 0.034 on the SRQS. The hope not only has a direct positive effect on the SRQS, but it can also indirectly affect the SRQS of by influencing the way of coping. The study, which was conducted by Jie Qin in 100 breast cancer survivors, confirmed that the improvement of SRQS can promote the level of hope. At the same time, a positive and optimistic attitude can promote the quality of ideal social relations. The results showed that a high level of hope among breast cancer survivors can properly face the reality of breast loss and maintain an optimistic attitude towards life. With a high level of hope, they actively cope with negative emotions and adverse reactions and seek support and help from family members. So the quality of their social relations was raised accordingly. Healthcare practitioners should guide patients to actively face the physical and mental distress caused by diseases.

The type $C$ personality and ADS of breast cancer survivors during chemotherapy were significantly negatively correlated $(r=-0.432, p<0.001)$, indicating that the behavior pattern of breast cancer survivors is more inclined to type $C$ personality, the lower the ADS, this is also the innovation of this research. In previous studies, the studies mainly focus on the negative correlation between type $\mathrm{C}$ personality and depression [17ه18]. This study shows that breast cancer survivors have type $\mathrm{C}$ personality behavior pattern, which is relatively fragile coping behavior pattern, and makes the level of adaptation to disability decline continuously. Therefore, healthcare practitioners can adjust their coping styles by changing the patient's type $\mathrm{C}$ behavior pattern and lifestyle.

In the path analysis results, the total effect of type $C$ personality on ADS is -1.311 , and the direct and indirect effects are -0.932 and -0.379 , respectively. Type $C$ personality not only has a direct negative effect on ADS, but also indirectly affects ADS by influencing acceptance-resignation. And the acceptanceresignation as an intermediary factor can explain the effect of $28.9 \%$ on ADS. The current studies show that the acceptance-resignation is significantly negatively correlated with ADS, which is consistent with the research of zhang [6]. When breast cancer survivors adopt acceptance-resignation, the adaptability of them to physical disabilities can be weakened. On the one hand, breast cancer survivors have a repressive and tolerant personality that makes it easier to accept negative cancer events. And the age of the patients is mostly between 45 and 59 years old, and the pursuit of reproductive function and beauty will have a higher acceptance level than that of young women who have not given birth. People with a type $\mathrm{C}$ personality are more inclined to adopt acceptance-resignation [35] and cannot actively treat the impact of breast cancer. Negative coping styles make patients stay in the stress and dilemma after breast cancer surgery and become a marginalized and disadvantaged group in society. The ability to adapt to return to society is gradually weakened, which seriously affects the quality of life of breast cancer survivors.

\subsection{Study limitations}


The present study has limitation : The study used convenience sampling to conduct a survey of breast cancer survivors from China, and the SRQS is closely related to ethnic culture, which may limit the applicability of the results to other populations except Asian countries, so promotion is possible will be restricted. In the future, researchers can expand the study site to different nationalities and races to test its effectiveness.

\subsection{Clinical implications}

The study findings suggest that healthcare practitioners should consider the mediating role of coping strategies when formulating interventions to improve the SRQS and ADS among breast cancer survivors . In clinical practice, we can formulate targeted nursing intervention measures according to the research path to provide psychological counseling for breast cancer survivors.

\section{Conclusions}

In summary, this study found that the hope and type $C$ personality have both direct and indirect effects on the SRQS and ADS. Confrontation has a direct impact on SRQS, while acceptance-resignation also have a direct impact on ADS. When breast cancer survivors adopt proactive strategies to cope with the low hope level and cancer-prone type $C$ personality, the SRQS and the ADS are better. Healthcare practitioners should be aware of the coping strategies of breast cancer survivors, and psycho-social interventions and supportive care should focus on these cognitive and emotional processes to improve SRQS and ADS for this population. At the same time, it can provide a further understanding of the influence of hope, ADS and SRQS among Chinese breast cancer survivors.

\section{Declarations}

\section{Funding}

This work waas supported by College Students Innovation and Entrepreneurship Training Program of Harbin Medical University [grant numbers :201810226123].

\section{Conflicts of interest}

The authors declare no conflicts of interest.

\section{Availability of data and material}

The data that support the findings of this study are available from the corresponding author upon reasonable request.

Code availability: (software application or custom code): N/A

\section{Authors' contributions}


Xiaoying Shen contributed to the study design and conception and revised the first manuscript. Material preparation, and analysis were performed by Runna Miao, Yuping Lin. The first draft of the manuscript was written by Runna Miao and all authors commented on previous versions of the manuscript. Hui Sun and Wei Yang contributed to data collection. All authors have read and approved the submitted version of the manuscript.

\section{Ethics approval}

Ethical approval for this study was obtained from the Research Ethics Committee at Harbin Medical University (NO.KY2019-0118). Informed consent was obtained before patients were recruited into this study.

\section{Consent to participate:}

All participants signed informed consent forms.

\section{Consent for publication:}

All authors agree to submit and publish the work in Supportive Care in Cancer.

\section{Acknowledgements}

We appreciate all the participants who showed great patience in answering the questionnaires and the nurses who assisted the researcher to approach the potential participants. This work was supported by College Students Innovation and Entrepreneurship Training Program of Harbin Medical University [grant numbers :201810226123].

\section{References}

1. Sung H, Ferlay J, Siegel RL, Laversanne M, Soerjomataram I, Jemal A, Bray F (2021) Global cancer statistics 2020: GLOBOCAN estimates of incidence and mortality worldwide for 36 cancers in 185 countries. CA Cancer J Clin. http://doi.org/10.3322/caac.21660 .

2. Bray F, Ferlay J, Soerjomataram I, Siegel RL, Torre LA, Jemal A (2018) Global cancer statistics 2018 : GLOBOCAN estimates of incidence and mortality worldwide for 36 cancers in 185 countries. CA Cancer J Clin 68:394-424. http://doi.org/10.3322/caac.21492 .

3. Zhang HT, Zhu XL, Jiang Y, Qin HY (2020) Longitudinal study of symptom distress in breast cancer patients before and one year after surgery. Journal of Chin J Mod Nurs:299-305

4. Bozo Ö, Tathan E, Yılmaz T (2014) Does Perceived Social Support Buffer the Negative Effects of Type C Personality on Quality of Life of Breast Cancer Patients? Soc Indic Res 119:791-801. http://doi.org/10.1007/s11205-013-0503-8 .

5. Pahlevan SS, Lehto RH, Amiri M, Ahadzadeh AS, Sharif NH, Haghdoost AA, Khoshnavay FF, Goudarzian AH (2021) Spirituality and quality of life in women with breast cancer: The role of hope 
and educational attainment. Palliat Support Care 19:55-61.

http://doi.org/10.1017/S1478951520000383 .

6. Zhang Q, Xiao S, Yan L, Sun L, Wang Y, Huang M (2019) Psychosocial Predictors of Adjustment to Disability Among Patients With Breast Cancer: A Cross-Sectional Descriptive Study. J Nurs Res 27:e15. http://doi.org/10.1097/jnr.0000000000000283 .

7. Kohler M, Steinmann E, Maximilian MH, Pedersen A, Goebel S (2020) The importance of social relationships for brain tumor patients' quality of life: A case for the inclusion of the concept of disclosure in psycho-oncological care. J Psychosoc Oncol 38:310-27. http://doi.org/10.1080/07347332.2019.1642283 .

8. Merluzzi TV, Serpentini S, Philip EJ, Yang M, Salamanca-Balen N, Heitzmann Ruhf CA, Catarinella A (2019) Social relationship coping efficacy: A new construct in understanding social support and close personal relationships in persons with cancer. Psycho-Oncology 28:85-91. http://doi.org/10.1002/pon.4913 .

9. Hou WK, Lam WWT, Law CC, Fu YT, Fielding R (2009) Measuring social relational quality in colorectal cancer: the Social Relational Quality Scale (SRQS). Psycho-Oncology 18:1097-105. http://doi.org/10.1002/pon.1500 .

10. Hou WK, Lam WW, Fielding R (2009) Adaptation process and psychosocial resources of Chinese colorectal cancer patients undergoing adjuvant treatment: a qualitative analysis. Psychooncology 18:936-44. http://doi.org/10.1002/pon.1457 .

11. Rustøen T, Lerdal A, Gay C, Kottorp A (2018) Rasch analysis of the Herth Hope Index in cancer patients. Health Qual Life Out 16. http://doi.org/10.1186/s12955-018-1025-5 .

12. Rock EE, Steiner JL, Rand KL, Bigatti SM (2014) Dyadic influence of hope and optimism on patient marital satisfaction among couples with advanced breast cancer. Support Care Cancer 22:2351-9. http://doi.org/10.1007/s00520-014-2209-0 .

13. Qing J, Jiang WL, Zhang Q, Li XL, Shen L (2017) Correlation between early postoperative social relationship quality and hope level in breast cancer patients. Modern Clinical Nursing 16:10-3.

14. Cardenal V, Ortiz-Tallo M, Martin FI, Martinez LJ (2008) Life stressors, emotional avoidance and breast cancer. Span J Psychol 11:522-30.

15. Eskelinen M, Ollonen P (2011) Assessment of 'cancer-prone personality' characteristics in healthy study subjects and in patients with breast disease and breast cancer using the commitment questionnaire: a prospective case-control study in Finland. Anticancer Res 31:4013-7.

16. Bu ZQ, Sha LS, Ding SH (2008) Research Progress of relation between tumor and C-type behavior.China Prac Med :189-91.

17. Wei M, Guo L, Zhu Y, Guo Y, Yv S, Namassevayam G, Xue W, Li J, Li L, Shen Z, Yv J, Zhu Z, Wang W, Liu Y, Zhao J, Chen F (2019) Type C Personality and Depression Among Newly Diagnosed Breast Cancer Patients: The Mediating Role of Sense of Coherence. Volume 15:3519-29. http://doi.org/2147/NDT.S230278 . 
18. Bozo Ö, Ar Y, Eldoğan D (2019) Does Marital Adjustment Mediate Type C Personality-Depressive Symptoms Relation? A Comparison between Breast Cancer Patients and Cancer-Free Women. Curr Psychol 38:1310-7. http://doi.org/1007/s12144-017-9693-6 .

19. Zhou CL, Wu YN, Li WJ, Li N, Ji X, Li XJ, Zhou X (2016) Correlation study between personality traits and chemotherapy related symptoms in patients with breast cancer dur-ing postoperative chemotherapy. Chinese Nursing Research 30:1812-5.

20. Dunn DS, Elliott TR (2005) Revisiting a Constructive Classic: Wright's Physical Disability: A Psychosocial Approach. Rehabil Psychol 50:183-9. http://doi.org/1037/0090-5550.50.2.183 .

21. Durá-Ferrandis E, Mandelblatt JS, Clapp J, Luta G, Faul L, Kimmick G, Cohen HJ, Yung RL, Hurria A (2017) Personality, coping, and social support as predictors of long-term quality-of-life trajectories in older breast cancer survivors: CALGB protocol 369901 (Alliance). Psycho-Oncology 26:1914-21. http://doi.org/10.1002/pon.4404 .

22. Li CQ, Wang MD (2019) Mediating effect of medical coping style in hope level and psychological elasticity of patients with postoperative radiotherapy for cervical cancer. J Prev Med Chin PLA 37:989.

23. Yuan YY, Yang FG, Huang X, Wang SY, Cao LN, Liang Y (2016) The mediating effects of coping style between acceptance of disability and quality of life among patients with a permanent colostomy. Journal of Nursing Science 31:465-7.

24. Zhao HP, Wang J (2000) Social support and hope for hemodialysis patients. Chin J Mod Nurs : 49-51

25. Yan H (2017) How the TCM Comprehensive Therapy Affect The Quality of Life for post operative Breast Cancer Patients.2017, Jiangsu: Nanjing University of Traditional Chinese Medicine

26. Shen XH, Jiang QJ (2000) Report on application of Chinese version of MCMQ in 701 patients. Chinese Journal of Behavioral Medical Science :22-4.

27. Chen N, Cheng Y, Sun XC, H JJ (2009) Relationship between acceptance of disability and posttraumatic stress response in patients with brachial plexus injury. Chin J Mod Nurs 44:677-80.

28. 28. Hu L, Bentler PM (1999) Cutoff criteria for fit indexes in covariance structure analysis: Conventional criteria versus new alternatives. Structural equation modeling 6:1-55. http://doi.org/1080/10705519909540118 .

29. Zhang J, Gao W, Wang P, Wu ZH (2010) Relationships among hope, coping style and social support for breast cancer patients. Chin Med J (Engl) 123:2331-5.

30. Wu Z, Liu Y, Li X, Li X (2016) Resilience and Associated Factors among Mainland Chinese Women Newly Diagnosed with Breast Cancer. Plos One 11:e167976. http://doi.org/10.1371/journal.pone.0167976 .

31. Hou WK, Lau KM, Shum T, Cheng A, Lee T (2018) Do concordances of social support and relationship quality predict psychological distress and well-being of cancer patients and caregivers? Eur J Cancer Care (Engl) 27:e12857. http://doi.org/10.1111/ecc.12857 .

32. Reblin M, Donaldson G, Ellington L, Mooney K, Caserta M, Lund D (2016) Spouse cancer caregivers' burden and distress at entry to home hospice: The role of relationship quality. J Soc Pers Relat 
33:666-86. http://doi.org/1177/0265407515588220 .

33. Yeung N, Lu Q, Mak W (2019) Self-perceived burden mediates the relationship between self-stigma and quality of life among Chinese American breast cancer survivors. Support Care Cancer 27:333745. http://doi.org/1007/s00520-018-4630-2 .

34. Bedi M, Devins GM (2016) Cultural considerations for South Asian women with breast cancer. J Cancer Surviv 10:31-50. http://doi.org/1007/s11764-015-0449-8 .

35. Niu J, Cui J, Yang K, Wang JM, Li HL, Yin CG (2020) Effect of type C personality behavior pattern on psychological resilience and benefit finding level of breast cancer patients after surgery.Chinese Nursing Reserch 34:3606-10.

36. Li JH (2018) Investigation On Social Anxiety Status and Its Relationship with the Acceptance of Disability and Coping Style in Breast Cancer Patients after Radical Surgery. North China University of Science and Technology.

37. Xiao S, Sun LY, Zhang QY, Wang Q (2017) The influencing factors of acceptance of disability among postoperative patients with breast cancer. Journal of Nursing Administration. 17:335-7.

38. Lin ZD, Zheng GW (2020) Study on the Correlation between Disability Acceptance and Quality of Life in Patients with Breast Cancer after Operation. Today Nurse 27:22-5.

\section{Tables}

TABLE 1 Participant characteristics $(n=141)$ 


\begin{tabular}{|c|c|}
\hline Characteristics & $\mathrm{n}(\%), \mathrm{M}(\mathrm{SD})$ \\
\hline Agelyear) & \\
\hline $\begin{array}{c}045 \\
45-59\end{array}$ & $29(20.5 \%)$ \\
\hline $\begin{array}{c}45-59 \\
\geq 60\end{array}$ & $26(18.44)$ \\
\hline Education level & \\
\hline Primary & $86(60.99)$ \\
\hline Secondary & $31(21.99)$ \\
\hline University & $24(17.02)$ \\
\hline Religious beliefs & \\
\hline Yes & $29(20.57)$ \\
\hline No & $112(79.43)$ \\
\hline Marital status & \\
\hline Married & $127(90.07)$ \\
\hline Unmarried & $4(2.84)$ \\
\hline Divorced & $10(7.09)$ \\
\hline Residence & \\
\hline City & $32(22.70)$ \\
\hline Countryside/town & $99(70.21)$ \\
\hline Monthly household income (Chinese, $¥$ ) & \\
\hline$\square 3000$ & $101(71.63)$ \\
\hline $3000-5000$ & $26(18.44)$ \\
\hline$\geq 5000$ & $14(9.93)$ \\
\hline Insurance & \\
\hline Yes & $137(97.16)$ \\
\hline No & $4(2.84)$ \\
\hline Menopause & \\
\hline Yes & $74(52.48)$ \\
\hline No & $67(47.52)$ \\
\hline Time since of cancer diagnosis & \\
\hline$\square 3$ month & $32(22.70)$ \\
\hline 3-6 month & $34(24.11)$ \\
\hline 6-12 month & $10(7.09)$ \\
\hline$\geq 12$ month & $65(46.10)$ \\
\hline Type of breast surgery & \\
\hline Modified radical surgery & $89(63.12)$ \\
\hline Simple mastectomy+sentinel lymph node biopsy & $52(36.88)$ \\
\hline Breast cancer site & \\
\hline Left & $64(45.39)$ \\
\hline Right & $70(49.65)$ \\
\hline Bilateral & $7(4.96)$ \\
\hline
\end{tabular}

Table 2 Descriptive statistics and bivariate correlation for the variables of interest 
2

3

4

5

\begin{tabular}{ll}
6 & 7 \\
\hline
\end{tabular}

Iope

.ype C personality

MCMQ Confrontation

1. Avoidance

1. Acceptance-

Resignation

iocial Relational Quality

Icceptance of Disability

$37.110 \pm 4.375$

$19.580 \pm 4.248 \quad .181^{*} \quad .084$

$\begin{array}{lllll}15.740 \pm 3.571 & .087 & .151 & .103 & -\end{array}$

$8.050 \pm 2.962 \quad-.205^{*} \quad .460^{* *} \quad .078 \quad .123 \quad-$

$54.490 \pm 5.844 \quad .630^{* *}-.206^{*} .249^{* *} .105-.219^{* *} \quad$ -

$82.210 \pm 11.211 .308^{* *}-.423^{* *}-.017-.032-.400^{* *} .200^{*}-$

MCMQ:Medical Coping Modes Questionnaire.

**. $\mathrm{P}<0.01, \quad * . \mathrm{P}<0.05$

TABLE 3 Total effects, indirect effects, direct effects among Hope, Type C personality, Medical Coping Modes,

Social Relational Quality,Acceptance of Disability

Variable

Point Product of

Estimate

Coefficients

Bootstrapping

\begin{tabular}{|c|c|c|c|c|c|c|c|}
\hline \multirow{3}{*}{ Variable } & \multirow{3}{*}{$\begin{array}{l}\text { Point } \\
\text { Estimate }\end{array}$} & \multirow{2}{*}{\multicolumn{2}{|c|}{$\begin{array}{l}\text { Product of } \\
\text { Coefficients }\end{array}$}} & \multicolumn{4}{|c|}{ Bootstrapping } \\
\hline & & & & \multicolumn{2}{|c|}{ BC 95\% CI } & \multicolumn{2}{|c|}{$\begin{array}{c}\text { Percentile } \\
95 \% \mathrm{CI}\end{array}$} \\
\hline & & $\mathrm{SE}$ & $\mathrm{Z}$ & Lower & Upper & Lower & Upper \\
\hline \multicolumn{8}{|c|}{ Total Effects } \\
\hline Hope-Social relational & 0.841 & 0.081 & 10.383 & 0.683 & 1.008 & 0.685 & 1.013 \\
\hline Hope-Acceptance of & 0.502 & 0.217 & 2.313 & 0.049 & 0.915 & 0.083 & 0.940 \\
\hline Type C-Acceptance of & -1.311 & 0.257 & -5.101 & -1.898 & -0.871 & -1.827 & -0.805 \\
\hline \multicolumn{8}{|c|}{ Indirect Effects } \\
\hline Hope-Social relational & 0.034 & 0.025 & 1.360 & 0.001 & 0.106 & -0.001 & 0.096 \\
\hline $\begin{array}{l}\text { Type C-Acceptance of } \\
\text { disability }\end{array}$ & -0.379 & 0.124 & -3.056 & -0.637 & -0.145 & -0.624 & -0.141 \\
\hline \multicolumn{8}{|c|}{ Direct Effects } \\
\hline Hope-Confrontation & 0.176 & 0.087 & 2.023 & 0.005 & 0.347 & -0.002 & 0.357 \\
\hline Hope-Social relational & 0.807 & 0.081 & 9.963 & 0.644 & 0.976 & 0.645 & 0.979 \\
\hline $\begin{array}{l}\text { que } \\
\text { Confrontat } \\
\text { relation }\end{array}$ & 0.193 & 0.084 & 2.298 & 0.030 & 0.365 & 0.029 & 0.364 \\
\hline $\begin{array}{c}\text { Hope-Acceptance of } \\
\text { disability }\end{array}$ & 0.502 & 0.217 & 2.313 & 0.049 & 0.915 & 0.083 & 0.940 \\
\hline $\begin{array}{l}\text { Type C-Acceptance- } \\
\text { Resignation }\end{array}$ & 0.423 & 0.084 & 5.035 & 0.256 & 0.580 & 0.248 & 0.577 \\
\hline $\begin{array}{l}\text { Type C-Acceptance of } \\
\text { disability }\end{array}$ & -0.932 & 0.270 & -3.452 & -1.525 & -0.447 & -1.474 & -0.399 \\
\hline $\begin{array}{l}\text { Acceptance-Resignation- } \\
\text { Acceptance of disability }\end{array}$ & -0.895 & 0.304 & -2.944 & -1.463 & -0.235 & -1.533 & -0.358 \\
\hline
\end{tabular}




\section{Figures}

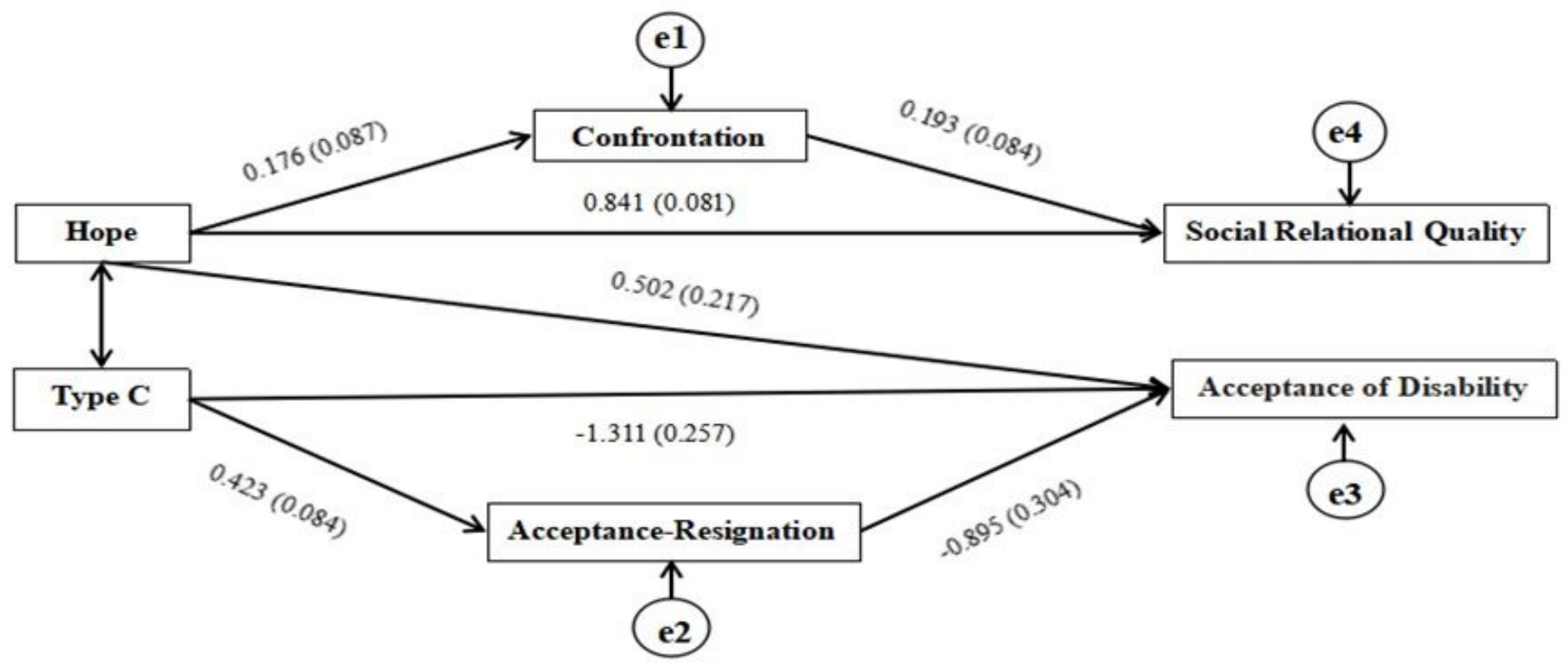

\section{Figure 1}

A structural model of the impact of hope, type $\mathrm{C}$ personality, and medical coping styles on the quality of breast cancer survivors' social relationships and acceptance of disability. The mediation model with standardized parameter estimates and standard errors in parentheses. Solid lines indicate significant paths at $p<0.05^{\star *}$

\section{Supplementary Files}

This is a list of supplementary files associated with this preprint. Click to download.

- database.xls 